\title{
Cerebral Amyloid Angiopathy: Multiple neurolgic problems
}

Seshanth Thabit* and Wadj Ahdaf Soueif .

Psychological Medicine Hospital, Egypt

Department of psychology,Mental Health in Cairo, Egypt.

*Corresponding Author :Seshanth Thabit, Psychological Medicine Hospital, Egypt. E-mail: paulgilbert@nff.org

Received date: August 02,2017 ;Accepted date : August 10,2017; Published date: August $18,2017$.

Citation: Seshanth Thabit, Cerebral Amyloid Angiopathy: Multiple neurolgic problems. J Psychology and Mental Health Care . Doi: http://dx.doi.org/ 10.31579.jpmhc/ 2637-8892.17/015.

Copyright : (c) 2017 Seshanth Thabit. This is an open-access article distributed under the terms of The Creative Commons Attribution License, which permits unrestricted use, distribution, and reproduction in any medium, provided the original author and source are credited.

Keywords: Amyloid angiopathy; White matter; Cerebral vasculitis

A 72-Year-old female with a history of migraine headaches presented with an acute onset of expressive aphasia, difficulty with memory and worsening of her headaches. An MRI of the brain was done which revealed diffuse white matter T2 hyperintensities (Figures 1). Due to worsening of the patient's clinical symptoms a repeat MRI was performed four days later that revealed multiple micro-bleeds (Figure 2), as well as a lobar hemorrhage in left temporal lobe (Figure 2). An extensive workup including HIV testing, CSF examination for infectious etiology including protein 14-3-3 and demylineating disease was negative. Paraneoplastic and autoimmune workup was also nondiagnostic. A brain biopsy was performed due to the extensive white matter disease, which revealed Cerebral Amyloid Angiopathy (CAA) with focal granulomatous angiitis. The patient was treated with intravenous steroids with no significant improvement clinically. Two months after diagnosis, her disease course has remained static, without improvement or deterioration.

Cerebral Amyloid Angiopathy can present as multiple neurolgic problems including seizures, transient neurologic deficits, cognitive decline and T2 Hyperintensities on MRI [1]. Pathologic examination reveals inflammation of CAA effected vessels [1]. The white matter lesions show progressive increase and may represent progressive microangiopathy due to CAA [2]. The likely underlying mechanism is vasculitic or non-vasculitic inflammatory reaction to amyloid-beta. Immunosuppressive therapy with steroids has been shown to be beneficial in both types, however slightly less beneficial in vasculitic type of reaction [3].
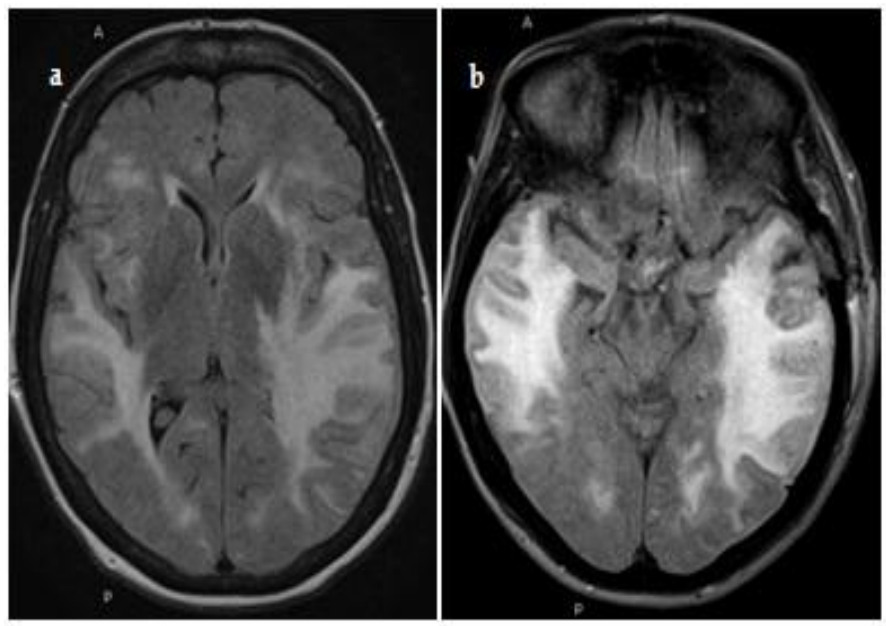

Figure 1: 1a \& 1b: Brain MRI Axial T2 Flair showing diffuse hyperintensities in white matter.

Auctores Publishing - Volume1-10015 www.auctoresonline.org

Page - 01

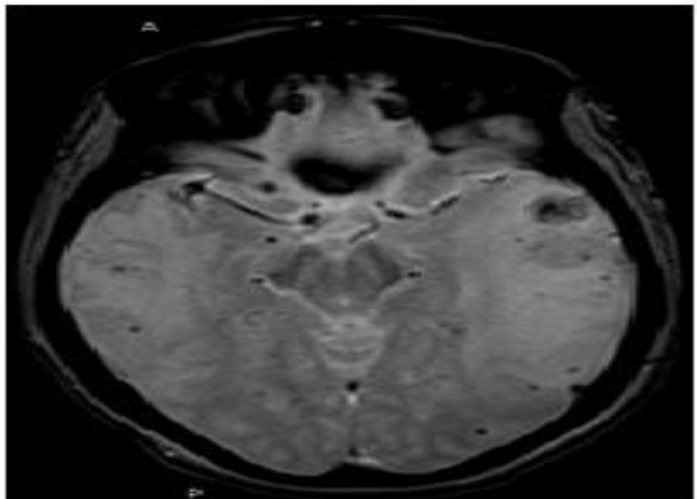

Figure 2: Brain MRI, Axial Gradiant echo image showing multiple hemosiderin deposits and Lobar hemmorhage in left temporal lobe

\section{References}

1. Kinnecom C, Lev MH, Wendell L, Smith EE, Rosand J, Frosch MP, et al. Course of cerebral amyloid angiopathy-related inflammation. Neurology. 2007;68(17):1411-6.

2. Chen YW, Gurol ME, Rosand J, Viswanathan A, Rakich SM, Groover TR, et al. Progression of white matter lesions and hemorrhages in cerebral amyloid angiopathy. Neurology. 2006;67(1):83-7.

3. Kloppenborg RP, Richard E, Sprengers ME, Troost D, $\begin{array}{llll}\text { Eikelenboom } & P, & \text { Nederkoorn } & \text { PJ. }\end{array}$ Steroid responsive encephalopathy in cerebral amyloid angiopathy: a case report and review of evidence for immunosuppressive treatment. J Neuroinflammation. 2010 Mar 9;7:18. doi: 10.1186/1742-2094-7-18. 